\title{
Religion, Spirituality, and Schizophrenia: A Review
}

\author{
Altaf Ahmad Malla ${ }^{1}$, Nasir Mohammad Bhat ${ }^{2 *}$
}

\section{ABSTRACT}

Religion and spirituality exert a significant role in the lives of many individuals, including people with schizophrenia. However, the contribution of religion and spirituality to various domains (psychopathology, explanatory models, treatment seeking, treatment adherence, outcome, etc.) has not received much attention. In this article, we review the exiting data with regards to the relationship of religion, spirituality, and various domains in patients with schizophrenia. Available evidence suggests that for some patients, religion instills hope, purpose, and meaning in their lives, whereas for others, it induces spiritual despair. Patients with schizophrenia also exhibit religious delusions and hallucinations. Further, there is some evidence to suggest that religion influences the level of psychopathology. Religion and religious practices also influence social integration, risk of suicide attempts, and substance use. Religion and spirituality also serves as an effective method of coping with the illness. Religion also influences the treatment compliance and outcome in patients with schizophrenia.

Keywords: Religion, schizophrenia, spirituality

Schizophrenia is often a chronic, disabling condition, associated with impairments in multiple domains of functioning. The usual treatment of schizophrenia is based on the biopsychosocial model, and involves the prescription of antipsychotic medications and psychological interventions for the patients and family intervention. ${ }^{[1]}$ This model of schizophrenia does not take into account the religious beliefs of the patient. However, religion and spirituality exert a significant role in the lives of people with schizophrenia. Keeping this in mind, the present review aims to evaluate the relationship of religion, spirituality, and schizophrenia.

For this review, electronic searches were conducted using PubMed, Science Direct, and Google Scholar. The search terms used were schizophrenia, religion, religiosity, religious practices, and spirituality. These terms were used in different combinations and all the relevant articles were identified. Articles which assessed various aspects of religion in relation to schizophrenia were included. However, we did not include the articles that assessed religion and caregivers of patients with schizophrenia.

\footnotetext{
${ }^{1}$ Institute of Mental Health and Neurosciences, Kashmir, India

${ }^{2}$ Institute of Mental Health and Neurosciences, Kashmir, India

*Responding Author

(c) 2015 I A Malla, N Bhat; licensee IJIP. This is an Open Access Research distributed under the terms of the Creative Commons Attribution License (http://creativecommons.org/licenses/by/2.0), which permits unrestricted use, distribution, and reproduction in any Medium, provided the original work is properly cited.
} 


\section{Religiousness/religious practices among patients with schizophrenia}

Studies have evaluated religious practices among patients with schizophrenia. A study from Switzerland suggested that about one-third of the patients with schizophrenia are very highly involved in religious community. Another $10 \%$ of the patients in same study were involved in minority religious movements. ${ }^{[2]}$ Another study from the same country reported that one-third of the patients were highly involved in a religious community, and another one third considered that spirituality had significant role in their life and they carried out spiritual practices every day, without getting involved in a religious community. ${ }^{[3]}$ Studies from other parts of the world which have assessed the religious practices of psychiatrically ill patients suggest that these are common in Europe ${ }^{[4,5]}$ and North America. ${ }^{[6,7]}$ A study found that as high as $91 \%$ of patients reported indulging in private religious or spiritual activities and $68 \%$ reported participation in public religious services or activities. ${ }^{[8]}$ Some studies which have compared religious practices in patients with schizophrenia and in the general population suggest that religious involvement is higher among patients, ${ }^{[9]}$ whereas others suggest that religious attendance is less in patients of schizophrenia. ${ }^{[10]}$

\section{Religion and psychopathology}

Among the various aspects of religion and spirituality, the influence of religion and spirituality on psychopathology has been one of the most explored areas of research. Broadly speaking, delusions and hallucinations of religious nature are further categorized as those with religious and supernatural themes. ${ }^{[11]}$ The religious delusions and hallucinations have a direct reference to organized religious themes (e.g., prayer, sin, possession) or religious figures (e.g., God, Jesus, devil, Prophet). The supernatural delusions and hallucinations have more general mystic references (e.g., black magic, spirits, demons, being bewitched, mythical forces, ghosts, sorcery, and voodoo). ${ }^{[11]}$ However, in the literature, delusions and hallucinations of either type are usually referred to as religious delusions.

Studies conducted among inpatients of schizophrenia suggest that the prevalence of religious delusions and hallucinations varies from country to country and the prevalence rates of the same vary from 6 to $63.3 \% .^{[12-16]}$ Studies which have compared religious delusions across different countries suggest that religious delusions are more common in Germany compared to Japan. ${ }^{\text {[13] }}$

Studies which have evaluated the delusional themes of various religious/spiritual delusions report that the common themes are that of persecution (by malevolent spiritual entities), influence (being controlled by spiritual entities), and self-significance (delusions of sin/ guilt or grandiose delusions). ${ }^{[17,18]}$ Studies also suggest that when the non-content dimensions (conviction, pervasiveness, preoccupation, action, inaction, and negative affect) of different types of delusions (persecutory, body/mind control, grandiose, thought broadcasting, religious, guilt, somatic, influence on others, jealousy, and other) are compared, findings suggest that religious delusions are held with more conviction and pervasiveness than other delusions. ${ }^{[12]}$ Data also suggest that patients with religious/spiritual delusions value religion as much as those 
without these types of delusions, but patients presenting delusions with religious content report receiving less support from religious communities. ${ }^{[18]}$

Studies which have evaluated the religion in the context of psychopathology suggest that Christian patients have more religious delusions, especially delusions of guilt and sin, than their counterparts belonging to other religions (Islam) ${ }^{[11]}$ Other studies have shown that compared to Christians, Buddhists have a lower frequency of religious themed delusions ${ }^{[19]}$ and that protestants experience more religious delusions than Catholics and those without religious affiliations. ${ }^{[20]}$ Another study reported higher prevalence of religious delusions of guilt in schizophrenia patients of Roman Catholic affiliations, when compared to Protestants and Muslims. ${ }^{[21]}$ Cross -cultural studies which have compared people from different ethnic backgrounds suggest that in case of paranoid delusions, Christian patients more often report persecutors to be supernatural beings, compared to Muslims and Buddhists patients. ${ }^{[21]}$ Other studies suggest that religious and supernatural themes in delusions are more common in Korean patients than Korean-Chinese patients or Chinese patients. ${ }^{[22]}$

Greenberg and Brom ${ }^{[23]}$ investigated hallucinations of patients belonging to Judaism and reported that hallucinations occurred more frequently during the night and this was linked to beliefs of the patients that they were more susceptible to evil spirits and demons at the night time. Peters et al. ${ }^{[24]}$ compared patients belonging to Hinduism (Hare Krishna followers), Christianity, and New Religious Movements with those of non-religious groups and found that patients from New Religious Movements scored higher on delusional measures than the other two groups. Other studies suggest that compared to the patients from Saudi Arabia, patients from the United Kingdom more clearly hear the religious-based auditory hallucinations. ${ }^{[25]}$

With regards to the relationship between religiosity and presence of religious delusions and hallucinations, findings are contradictory with some studies suggesting higher prevalence of religious delusions and hallucinations in those with higher religiosity ${ }^{[26]}$ and others suggesting lack of relationship between the two. ${ }^{[16]}$

With regard to socio-demographic variables, reports suggest that the religious content of delusions is related to the marital status and education of schizophrenic patients. ${ }^{[16]}$ Occasional studies suggest a relationship between religious delusions and cognitive deficits. ${ }^{[27]}$

Religious delusions influence help seeking, treatment, and outcome. Evidence suggests that those with religious delusions take longer to establish service contact, ${ }^{[28,29]}$ receive more medications, have overall higher symptom scores, and have poorer functioning. ${ }^{[2]}$ Those with religious delusion/hallucination are more likely to receive magico-religious healing, are not satisfied with psychiatric treatment ${ }^{[26]}$ and are more likely not to adhere to psychiatric treatment. ${ }^{[27]}$ Evidence also suggests that those with religious delusions have poor outcome ${ }^{[30,31]}$ and more frequently 
indulge in violence ${ }^{[32,33]}$ and self-harm. ${ }^{[34-36]}$ Some authors suggest that religious delusions can influence the health beliefs models and consequently lead to poor treatment compliance. ${ }^{[37]}$

In a review of 70 studies, the authors evaluated the relationship between religion, supernatural beliefs, and psychopathology. ${ }^{[11]}$ The authors reported that 30 out of the 70 studies (43\%) have found a relationship between delusions and hallucinations, and religion and the supernatural beliefs. Majority of the studies (27 of 30 studies) directly described religious delusions, of which 20 studies described delusions to be of a religion-based nature and 14 considered delusions to be of supernatural nature. Thirteen studies reported on religious hallucinations, with 11 having religious content and 9 finding more supernatural content. ${ }^{[11]}$

Many studies have evaluated the influence of religion on severity of psychopathology and the findings are contradictory. Some suggest that religious activities and beliefs are more in persons who experience more severe symptoms, especially psychotic and general symptoms, ${ }^{[38]}$ whereas others suggest that increased religious activity is associated with reduced level of symptoms. ${ }^{[39]}$ Data also suggest that higher religiosity is associated with absence of first-rank symptoms. ${ }^{[40]}$

\section{Relationship of religion and other clinical aspects in patients of schizophrenia}

Researchers have shown that religion/religiousness in patients with schizophrenia is associated with increased social integration, reduced risk of suicide attempts, ${ }^{[38,41]}$ reduce risk of substance use ${ }^{[38,42]}$ decreased rate of smoking, ${ }^{[43]}$ better quality of life, ${ }^{[10,44,45]}$ lower level of functioning, ${ }^{[26]}$ and better prognoses. ${ }^{[46]}$ With regard to the relationship of religion and psychosocial adaptation, the findings are contradictory, with some reporting better psychosocial adaptation ${ }^{[47]}$ and others reporting poor social and psychological status in a majority of patients. ${ }^{[9]}$ Religious support and spirituality has also been found to be associated with better recovery ${ }^{[22,48,49]}$ and reduced relapse rate ${ }^{[47,50]}$ However, in some patients, higher religiosity has been linked to higher risk of suicide attempt. $^{[38]}$

Religion and treatment adherence in schizophrenia Some studies suggest that religion/religiousness in patients with schizophrenia is associated with better treatment adherence with psychiatric treatment, ${ }^{[4,38,47]}$ whereas others suggest association of religion with poor treatment adherence. ${ }^{[38,51]}$ Some studies suggest that higher religiosity is associated with lower preference for psychiatric treatment.

\section{Religious coping in schizophrenia}

Religious coping is multidimensional and refers to functionally oriented expressions of religion in times of stress. Religious coping is operationally defined as "the use of religious beliefs or behaviors to facilitate problem-solving to prevent or alleviate the negative emotional consequences of stressful life circumstances." ${ }^{\text {"[2] }}$ The concept of religious coping has been refined and categorized as helpful or positive, harmful or negative, and with mixed implications. The positive religious coping strategies include religious purification/forgiveness, religious 
direction/conversion, religious helping, seeking support from clergy/members, collaborative religious coping, religious focus, active religious surrender, benevolent religious reappraisal, spiritual connection, and marking religious boundaries. The negative religious coping strategies include spiritual discontent, demonic reappraisal, passive religious deferral, interpersonal religious discontent, reappraisal of God's powers, punishing God reappraisal, and pleading for direct intercession. ${ }^{[53]}$ The religious coping strategies with mixed implications include religious rituals in response to crisis, self-directing, deferring, and pleading religious coping.

Few studies have evaluated the types of religious coping employed by patients with schizophrenia and their role in dealing with the stressful situation. ${ }^{[18,54,55]}$ Studies suggest that up to $80 \%$ of patients use religious coping as a means of dealing with their illness. ${ }^{[39]}$ Others have reported that in $45 \%$ of patients, spirituality and religiousness was helpful in coping with the illness. $^{[18]}$ Studies which have compared different disorders suggest that patients with schizophrenia, bipolar disorder, and schizoaffective disorder use religious coping for a significantly greater number of years and perceive the same to be more helpful than those diagnosed with depressive disorders. ${ }^{[56]}$

Studies also suggest that religious coping influences other parameters. Studies suggest that religious coping in patients of schizophrenia is associated positively with psychological and existential well-being, with positive religious coping being the primary predictor of psychological well-being. ${ }^{[57]}$ A study revealed that benevolent religious reappraisal was associated with better well-being, better adjustment, and lesser personal loss from mental illness, whereas punishing God reappraisal and reappraisal of God's powers were associated, with a greater correlation, with lesser well-being and adjustment and greater personal loss from mental illness. ${ }^{[58]}$ Positive religious coping has also been associated with higher quality of life in the domain of psychological health. ${ }^{[8]}$ Negative religious coping has been associated with lower quality of life ${ }^{[8]}$ and higher distress (assessed by Depression, Anxiety and Stress scale). ${ }^{[59]}$ Longitudinal studies have shown that higher salience of religion and use of positive religious coping at the baseline are predictive of lesser negative symptoms, better quality of life, and better clinical global impression. ${ }^{[49]}$ Participation in spiritual activities has been shown to be associated with better social functioning and dealing with negative symptoms. ${ }^{[60]}$

\section{Religion and explanatory models held by patients with schizophrenia}

Studies from different parts of the world have evaluated the explanatory models of illness held by the patients with schizophrenia and suggest that many patients have non-medical explanations for their illness. ${ }^{[61-65]}$ Most of the non-medical explanations across different studies pertain to the supernatural causes. The different explanations include obsession by witches or jinns, ${ }^{[61]}$ esoteric, ${ }^{[66]}$ spiritual, and mystical factors, ${ }^{[63]}$ family trouble, inner problems of self, economic difficulties, supernatural forces, ${ }^{[64]}$ sorcery, ghosts/evil spirit, spirit intrusion, divine wrath, planetary/astrological influences, dissatisfied or evil spirits, and bad deeds of the past. ${ }^{[65]}$ A study from India reported that about $66-70 \%$ of the patients have at least one non-biomedical 
explanatory model of supernatural type ${ }^{,[65]}$ whereas studies from other parts of the world have reported presence of supernatural explanatory models in about $10 \%$ of patients. ${ }^{[64]}$ A crosscultural study which included Arab-Islamic, Jordanian, and German patients suggests that Jordanian patients tend to believe more in esoteric factors underlying their illness, and they perceive the illness to be more threatening. ${ }^{[66]}$ Other studies suggest that Whites cited biological causes more frequently than African-Caribbeans and Bangladeshis, who cited social causes more frequently. ${ }^{[67]}$ Studies also suggest that non-medical explanatory models influence the insight ${ }^{[63]}$ and help seeking, ${ }^{[63,64]}$ and are associated with poor outcome. ${ }^{[62]}$

\section{Religion and quality of life of patients with schizophrenia}

The World Health Organization (WHO) considers spirituality, religion, and personal beliefs as an important area in the evaluation of the quality of life (QOL). ${ }^{[68]}$ The different mechanisms that have been proposed to link religiousness and spirituality to health outcome include behavioral (spirituality may be associated with a healthy lifestyle), social (religious groups provide supportive communities for their members), psychological (beliefs about God, ethics, human relationships, life and death), and physiological (religious practices elicit a relaxation response). Keeping the importance of religion and spirituality, the WHO designed a scale known as World Health Organization Quality of life-Spirituality, Religiousness, and Personal Belief scale (WHOQOL-SRPB). A study from our center suggests that spirituality and religiosity have an important influence on the overall QOL of patients with schizophrenia. ${ }^{[69]}$ The same group of authors also suggested a relationship between spirituality and religiosity domain of QOL, as assessed by WHOQOL-SRPB and the coping mechanisms used by the patients. ${ }^{[70]}$

\section{Religion and help-seeking behavior}

A study from India showed that many patients seek the help of faith healers to get rid of patient's symptoms $^{[71]}$ and it has also been shown that indigenous healing methods are considered complementary to the medical management of mental illness. ${ }^{[72]} \mathrm{A}$ survey of consecutive psychiatric patients attending a hospital in Tamil Nadu, South India showed that $58 \%$ of psychotic patients saw a religious healer prior to psychiatric consultation. ${ }^{[73]}$ In fact, some of the studies suggest that seeking religious help for mental disorders is often the first step in the management of mental disorders, as a result of cultural explanations for the illness. ${ }^{[74]}$ Studies from other parts of the world suggest that patients with schizophrenia who are admitted for long duration experience spiritual distress. ${ }^{[75]}$ Studies which have specifically evaluated religiosity suggest that higher religiosity is associated with lower preference for psychiatric treatment. ${ }^{[26]}$

\section{CONCLUSIONS AND FUTURE DIRECTIONS}

Despite the close relationship of religion with various aspects of schizophrenia, this area has been mostly ignored in mental health assessment, diagnoses, and treatment. ${ }^{[6]}$ The limited existing data show that religion has an influence on the expression of psychopathology, treatment-seeking behavior, as well as treatment outcome. Given the importance of religion and spirituality for many patients, biopsychosocial model of schizophrenia should integrate the same, 
in order to achieve a whole-person approach to treatment. Findings also suggest that clinicians are rarely aware of the importance of religiosity for patients, even if spirituality needs are to be integrated into patient care ${ }^{[76]}$ Hence, there is an urgent need to make the clinicians aware of this need of the patients and they should evaluate the religious and spiritual issues of their patients. There is a need to further evaluate this area, especially from cross-cultural perspective. It is hoped that understanding the relationship of religion with various aspects of schizophrenia will lead to better understanding of the patients by the clinicians, better organization of services as per the needs of the patients, and better outcome of the patients.

\section{REFERENCES}

1. $\quad$ Lalonde P. Schizophrénies. In: Lalonde PJ, Grundberg F, editor. Psychiatrie bio-psychosociale. Montréal: Gaëtan Morin; 1999. p. 242-85.

2. Huguelet P, Mohr S, Borras L, Gillieron C, Brandt PY. Spirituality and religious practices among outpatients with schizophrenia and their clinicians. Psychiatr Serv 2006;57:366-72.

3. Mohr S, Huguelet P. The relationship between schizophrenia and religion and its implications for care. Swiss Med Wkly 2004;134:369-76.

4. Kirov G, Kemp R, Kirov K, David AS. Religious faith after psychotic illness. Psychopathology 1998;31:234-45.

5. Neeleman J, Lewis G. Religious identity and comfort beliefs in three groups of psychiatric patients and a group of medical controls. Int J Soc Psychiatry 1994;40:12434.

6. $\quad$ Brewerton TD. Hyperreligiosity in psychotic disorders J Nerv Ment Dis 1994;182:302-4.

7. Kroll J, Sheehan W. Religious beliefs and practices among 52 psychiatric inpatients in Minnesota. Am J Psychiatry 1989;146:67-72.

8. Nolan JA, McEvoy JP, Koenig HG, Hooten EG, Whetten K, Pieper CF. Religious coping and quality of life among individuals living with schizophrenia. Psychiatr Serv 2012;63:1051-4.

9. Mohr S, Borras L, Nolan J, Gillieron C, Brandt PY, Eytan A, et al. Spirituality and religion in outpatients with schizophrenia: A multi-site comparative study of Switzerland, Canada, and the United States. Int J Psychiatry Med 2012;44:29-52.

10. Cohen CI, Jimenez C, Mittal S. The role of religion in the well-being of older adults with schizophrenia. Psychiatr Serv 2010;61:917-22.

11. Gearing RE, Alonzo D, Smolak A, McHugh K, Harmon S, Baldwin S. Association of religion with delusions and hallucinations in the context of schizophrenia: Implications for engagement and adherence. Schizophr Res 2011;126:150-63.

12. Appelbaum P, Robbins P, Roth L. Dimensional approach to delusions: Comparison across types of diagnoses. Am J Psychiatry 1999;156:1938-43.

13. Tateyama M, Asai M, Kamisada M, Hashimoto M, Bartels M, Heimann H. Comparison of schizophrenic delusions between Japan and Germany. Psychopathology 1993;26:1518. 
14. Stompe T, Friedman A, Ortwein G, Strobl R, Chaudhry HR, Najam N, et al. Comparison of delusions among schizophrenics in Austria and in Pakistan. Psychopathology 1999; 32:225-34.

15. Krzystanek M, Krysta K, Klasik A, Krupka-Matuszczyk I. Religious content of hallucinations in paranoid schizophrenia. Psychiatr Danub 2012;24 Suppl 1:S65-9.

16. Rudaleviciene P, Stompe T, Narbekovas A, Raskauskiene N, Bunevicius R. Are religious delusions related to religiosity in schizophrenia? Medicina (Kaunas) 2008;44:529-35.

17. Wilson W. Religion and psychosis. In: Koenig H, editor. Handbook of religion and mental health. San Diego: Academic Press; 1998. p. 161-73.

18. Mohr S, Borras L, Betrisey C, Pierre-Yves B, Gilliéron C, Huguelet P. Delusions with religious content in patients with psychosis: How they interact with spiritual coping. Psychiatry 2010;73:158-72.

19. Tateyama M, Asai M, Hashimoto M, Bartels M, Kasper S. Transcultural study of schizophrenic delusions: Tokyo versus Vienna versus Tubingen (Germany). Psychopathology 1998;31:59-68.

20. Getz GE, Fleck DE, Strakowski SM. Frequency and severity of religious delusions in Christian patients with psychosis. Psychiatry Res 2001;103:87-91.

21. Stompe T, Ortwein-Swoboda G, Chaudhry HR, Friedmann A, Wenzel T, Schanda H. Guilt and depression: A cross-cultural comparative study. Psychopathology 2001;34:28998.

22. Kim K, Li D, Jiang Z, Cui XJ, Lin L, Kang JJ. Schizophrenia delusions among Koreans, Korean-Chinese and Chinese: A transcultural study. Int J Soc Psychiatry 1993;39:190-9.

23. Greenberg D, Brom D. Nocturnal hallucinations in ultra-orthodox Jewish Israeli men. Psychiatry 2001;64:81-9.

24. Peters E, Day S, McKenna J, Orbach G. Delusional ideation in religious and psychotic populations. Br J Clin Psychol 1999;38:83-96.

25. Kent G, Wahass S. The content and characteristics of auditory hallucinations in Saudi Arabia and the UK: A cross-cultural comparison. Acta Psychiatr Scand 1996;94:433-7.

26. Huang CL, Shang CY, Shieh MS, Lin HN, Su JC. The interactions between religion, religiosity, religious delusion/hallucination, and treatment-seeking behavior among schizophrenic patients in Taiwan. Psychiatry Res 2011;187:347-53.

27. Rocca P, Castagna F, Marchiaro L, Rasetti R, Rivoira EF. Neuropsychological correlates of reality distortion in schizophrenic patients. Psychiatry Res 2006;145:49-60.

28. Siddle R, Haddock G, Tarrier N, Faragher EB. Religious delusions in patients admitted to hospital with schizophrenia. Soc Psychiatry Psychiatr Epidemiol 2002;37:130-8.

29. Moss Q, Fleck DE, Strakowski SM. The influence of religious affiliation on time to first treatment and hospitalization. Schizophr Res 2006;84:421-6.

30. Thara R, Eaton WW. Outcome of schizophrenia: The Madras longitudinal study. Aust N Z J Psychiatry 1996;30:516-22. 
31. Doering S, Muller E, Kopcke W, Pietzcker A. Gaebel W. Linden M, et al. Predictors of relapse and rehospitalization in schizophrenia and schizoaffective disorder. Schizophr Bull 1998; 24:87-98.

32. Kraya NA, Patrick C. Folie à deux in forensic setting. Aust N Z J Psychiatry1997;31:883-8.

33. Silva JA, Leong GB, Weinstock R. Violent behaviors associated with the antichrist delusion. J Forensic Sci 1997;42:1058-61.

34. Field H, Waldfogel S. Severe ocular self-injury. Gen Hosp Psychiatry 1995;17:224-7.

35. Waugh AC. Autocastration and biblical delusions in schizophrenia. Br J Psychiatry 1986;149:656-8.

36. Kushner AW. Two cases of auto-castration due to religious delusions. Br J Med Psychol 1967;40:293-8.

37. Kelly G, Maimon J, Scott J. Utility of the health belief model in examining medication compliance among psychiatric outpatients. Soc Sci Med 1987;25:1205-11.

38. Mohr S, Brandt PY, Borras L, Gilliéron C, Huguelet P. Toward an integration of spirituality and religiousness into the psychosocial dimension of schizophrenia. Am J Psychiatry 2006;163:1952-9.

39. Tepper L, Rogers SA, Coleman EM, Malony HN. The prevalence of religious coping among persons with persistent mental illness. Psychiatr Serv 2001;52:660-5.

40. Littlewood R, Lipsedge M. Acute psychotic reactions in Caribbean-born patients. Psychol Med 1981;11:303-18.

41. Huguelet P, Mohr S, Jung V, Gillieron C, Brandt PY, Borras L. Effect of religion on suicide attempts in outpatients with schizophrenia or schizo-affective disorders compared with inpatients with non-psychotic disorders. Eur Psychiatry 2007;22:188-94.

42. Huguelet P, Borras L, Gillieron C, Brandt PY, Mohr S. Influence of spirituality and religiousness on substance misuse in patients with schizophrenia or schizo-affective disorder. Subst Use Misuse 2009;44:502-13.

43. Borras L, Mohr S, Brandt PY, Gillieron C, Eytan A, Huguelet P. Influence of spirituality and religiousness on smoking among patients with schizophrenia or schizo-affective disorder in Switzerland. Int J Soc Psychiatry 2008;54:539-49.

44. Gaite L, Vázquez-Barquero JL, Borra C, Ballesteros J, Schene A, Welcher B, et al. Quality of life in patients with schizophrenia in five European countries: The EPSILON study. Acta Psychiatr Scand 2002;105:283-92.

45. Murray-Swank A, Goldberg R, Dickerson F, Medoff D, Wohlheiter K, Dixon L. Correlates of religious service attendance and contact with religious leaders among persons with co-occurring serious mental illness and type 2 diabetes. J Nerv Ment Dis 2007;195:382-8.

46. Flics DH, Herron WG. Activity-withdrawal, diagnosis, and demographics as predictors of premorbid adjustment. J Clin Psychol 1991;47:189-98.

47. Huguelet P, Binyet-Vogel S, Gonzalez C, Favre S, McQuillan A. Follow-up study of 67 first episode schizophrenic patients and their involvement in religious activities. Eur Psychiatry 1997;12:279-83. 
48. Webb M, Charbonneau AM, McCann RA, Gayle KR. Struggling and enduring with God, religious support, and recovery from severe mental illness. J Clin Psychol 2011;67:116176.

49. Mohr S, Perroud N, Gillieron C, Brandt PY, Rieben I, Borras L, et al. Spirituality and religiousness as predictive factors of outcome in schizophrenia and schizo-affective disorders. Psychiatry Res 2011;186:177-82.

50. Rund BR. Fully recovered schizophrenics: A retrospective study of some premorbid and treatment factors. Psychiatry 1990;53:127-39.

51. Borras L, Mohr S, Brandt PY, Gilliéron C, Eytan A, Huguelet P. Religious beliefs in schizophrenia: Their relevance for adherence to treatment. Schizophr Bull 2007;33:123846.

52. Koenig H. Handbook of religion and mental health. San Diego: Academic Press; 1998.

53. Pargament KI, Koenig HG, Perez LM. The many methods of religious coping: Development and initial validation of the RCOPE. J Clin Psychol 2000;56:519-43.

54. Smolak A, Gearing RE, Alonzo D, Baldwin S, Harmon S, McHugh K. Social Support and Religion: Mental Health Service Use and Treatment of Schizophrenia. Community Ment Health J 2013;49:444-50.

55. Smith S, Suto MJ. Religious and/or spiritual practices: Extending spiritual freedom to people with schizophrenia. Can J Occup Ther 2012;79:77-85.

56. Reger GM, Rogers SA. Diagnostic differences in religious coping among individuals with persistent mental illness. J Psychol Christianity 2002;21:341-8.

57. Pieper JZ. Religious coping in highly religious psychiatric inpatients. Ment Health Relig Cult 2004;7:349-63.

58. Phillips R, Stein C. God's will, God's punishment, or God's limitations? Religious coping strategies reported by young adults living with serious mental illness. J Clin Psychol 2007;63:529-40.

59. Nurasikin MS, Khatijah LA, Aini A, Ramli M, Aida SA, Zainal NZ, et al. Religiousness, religious coping methods and distress level among psychiatric patients in Malaysia. Int J Soc Psychiatry 2013;59:332-8.

60. Revheim N, Greenberg WM, Citrome L. Spirituality, schizophrenia, and state hospitals: Program description and characteristics of self-selected attendees of a spirituality therapeutic group. Psychiatr Q 2010;81:285-92.

61. Napo F, Heinz A, Auckenthaler A. Explanatory models and concepts of West African Malian patients with psychotic symptoms. Eur Psychiatry 2012;27 Suppl 2:S44-9.

62. Johnson S, Sathyaseelan $\mathrm{M}$, Charles $\mathrm{H}$, Jeyaseelan V, Jacob KS. Insight, psychopathology, explanatory models and outcome of schizophrenia in India: A prospective 5-year cohort study. BMC Psychiatry 2012;12:159.

63. Saravanan B, Jacob KS, Johnson S, Prince M, Bhugra D, David AS. Belief models in first episode schizophrenia in South India. Soc Psychiatry Psychiatr Epidemiol 2007;42:446-51. 
64. Unal S, Kaya B, Yalvaç HD. Patients' explanation models for their illness and helpseeking behavior. Turk Psikiyatri Derg 2007 Spring;18:38-47.

65. Kate N, Grover S, Kulhara P, Nehra R. Supernatural beliefs, aetiological models and help seeking behaviour in patients with schizophrenia. Ind Psychiatry J 2012;21:49-54.

66. Conrad R, Schilling G, Najjar D, Geiser F, Sharif M, Liedtke R. Cross-cultural comparison of explanatory models of illness in schizophrenic patients in Jordan and Germany. Psychol Rep 2007;101:531-46.

67. McCabe R, Priebe S. Explanatory models of illness in schizophrenia: Comparison of four ethnic groups. Br J Psychiatry 2004;185:25-30.

68. Culliford L. Spirituality and clinical care. BMJ 2002;325:1434-5.

69. Shah R, Kulhara P, Grover S, Kumar S, Malhotra R, Tyagi S. Contribution of spirituality to quality of life in patients with residual schizophrenia. Psychiatry Res 2011;190:200-5.

70. Shah R, Kulhara P, Grover S, Kumar S, Malhotra R, Tyagi S. Relationship between spirituality/religiousness and coping in patients with residual schizophrenia. Qual Life Res 2011;20:1053-60.

71. Kulhara P, Avasthi A, Sharma A. Magico-religious beliefs in schizophrenia: A study from north India. Psychopathology 2000;33:62-8.

72. Saravanan B, Jacob KS, Deepak MG, Prince M, David AS, Bhugra D. Perceptions about psychosis and psychiatric services: A qualitative study from Vellore, India. Soc Psychiatry Psychiatr Epidemiol 2008;43:231-8.

73. Compion J, Bhugra D. Experiences of religious healing in psychiatric patients in South India. Soc Psychiatry Psychiatr Epidemiol 1997;32:215-21.

74. Padmavati R, Thara R, Corin E. A qualitative study of religious practices by chronic mentally ill and their caregivers in South India. Int J Soc Psychiatry 2005;51:139-49.

75. Yang CT, Narayanasamy A, Chang SL. Transcultural spirituality: The spiritual journey of hospitalized patients with schizophrenia in Taiwan. J Adv Nurs 2012;68:358-367.

76. Borras L, Khazaal Y, Khan R, Mohr S, Kaufmann YA, Zullino D, et al. The relationship between addiction and religion and its possible implication for care. Subst Use Misuse 2010; 45:2357-410. 